\title{
UJI MIKROBIOLOGI AIR SUMUR GALI DI WILAYAH KEBON SARI KELURAHAN KAMPUNG BARU DENGAN TEKNIK TABUNG GANDA
}

\author{
A.A.Ngr.Hendra Darma \\ Universitas Pendidikan Ganesha \\ Singaraja, Indonesia \\ e-mail: darma4hendra@gmail.com
}

\begin{abstract}
Abstrak
Penelitian ini adalah penelitian deskriptif yang bertujuan untuk (1) menganalisis ada tidaknya bakteri coliform tinja pada air sumur gali di wilayah Kebon Sari kelurahan Kampung Baru, (2) mengetahui nilai MPN ( Most Probable Number) air sumur gali di wilayah Kebon kelurahan Kampung Baru. Populasi penelitian ini adalah sumur di wilayah Kebon Sari kelurahan Kampung Baru Kabupaten Buleleng, sedangkan yang dijadikan sampel adalah sebanyak 9 sumur. Penetapan sampel dilakukan dengan teknik Area Sampling. Data tentang kandungan bakteri coliform tinja dan nilai MPN dianalisis di laboratorium PDAM Kabupaten Buleleng. Data yang diperoleh dianalisis secara deskriptif. Hasil penelitian menunjukkan (1) air sumur gali di wilayah Kebon Sari Kelurahan Kampung Baru positif mengandung bakteri Coliform tinja dengan menggunakan teknik tabung ganda, (2) nilai MPN air sumur gali di wilayah Kebon Sari Kelurahan Kampung Baru sebesar 218 yang yang menunjukkan air sumur gali tersebut beresiko untuk air minum apabila dikonsumsi secara langsung.
\end{abstract}

Kata kunci: Uji Mikrobiologi, Air Sumur Gali, Teknik Tabung Ganda

\section{Pendahuluan}

Setiap mahkluk hidup di dunia ini tanpa terkecuali sangat menggantungkan hidupnya pada air. Khususnya manusia, air selain sebagai konsumsi makan dan minum juga diandalkan untuk keperluan pertanian, industri, dan lain-lain. Namun seiring dengan semakin bertambahnya jumlah penduduk, kebutuhan akan air minum semakin meningkat, dan kegiatan atau aktivitas manusia akan bertambah pula yang akan mengakibatkan meningkatnya pencemaran. Ternyata kebutuhan akan air untuk keperluan sehari-hari berbeda untuk tiap tempat, tingkatan kehidupan atau tiap bangsa dan negara.

Dalam memenuhi kebutuhan akan air, khususnya air minum, sebagian besar manusia masih mengambil dari sumber-sumber air yang ada didekatnya, seperti halnya air sumur, di samping sumber air lainnya seperti kolam, sungai, mata air, air hujan dan tidak kalah pentingnya air yang bersumber dari PDAM.

Sumur gali merupakan salah satu alternatif dalam memenuhi kebutuhan akan air minum dan pemanfaatannya masih banyak ditemukan, baik di daerah perkotaan ataupun di pedesaan. Tetapi sebagian besar penduduk belum mengindahkan kualitas dari air sumur gali yang dimanfaatkan baik dilihat dari parameter fisik, kimia, dan mikrobiologinya. Selain itu kedalaman dari sumur gali yang dibuat relatif tidak terlalu dalam, yaitu 2 - $15 \mathrm{~m}$. Dengan demikian kemungkinan air tercemari oleh pengotor, kuman penyakit, atau bahan-bahan beracun sangat berpeluang besar. Pencemar-pencemar ini dapat bersumber dari limbah domestik seperti limbah rumah tangga, perkampungan, kota, pasar, jalan dan sebagainya, ataupun yang bersumber dari non domestik seperti limbah pabrik, industri, pertanian, peternakan, perikanan serta sumber-sumber lainnya, sehingga perlu memperhatikan persyaratan sanitasi.

$\mathrm{Di}$ daerah perkotaan, persyaratan sanitasi tersebut belum dapat terlaksana, dikarenakan daerah pemukiman yang relatif sempit akibat keterbatasan daerah pemukiman yang tersedia. Pembuatan sumur gali dilakukan tanpa memperhatikan syarat konstruksi dan syarat lokasi, seperti halnya sumur-sumur yang terdapat di wilayah Kebon Sari Kelurahan Kampung Baru, kecamatan Buleleng Kabupaten Buleleng. 
Dari hasil observasi yang dilakukan peneliti, sebagian besar penduduk telah menggunakan air PDAM sebagai sumber air minum, namun ada beberapa penduduk yang masih menggunakan sumur gali sebagai sumber air minum. Sumur sumur yang dibuat tersebut berdekatan dengan sumber pencemar seperti comberan, resapan kakus. Hal itu dapat menyebabkan air sumur mengandung bakteri pantogen seperti bakteri Coliform tinja.

Bakteri Coliform tinja berasal dari kotoran manusia ataupun hewan berdarah panas, yang merupakan salah satu indikator tercemarnya air selain indikator fisik dan kimia. Terdapatnya bakteri Coliform tinja pada air, akan dapat menyebabkan berbagai penyakit yang membahayakan diantaranya adalah typhus, para thypus, disentri dan cholera.

Dalam penelitian ini terdapatnya bakteri Coliform tinja di dalam air sebagai pencemar dapat diketahui keberadaannya, dengan menggunakan teknik tabung ganda. Sedangkan penentuan tingkat resiko yang ditimbulkan dapat diketahui dari nilai MPN (Most Probable Number).

Berdasarkan keputusan Menteri Kesehatan RI Nomor 907/MENKES/VII/2002 tentang syarat-syarat dan pengawasan kualitas air minum, menyatakan bahwa kandungan Coliform total dan Coliform tinja dalam air adalah 0 . Dengan demikian adanya bakteri Coliform tinja pada air sumur gali yang manfaatkan sebagai sumber air minum penting untuk diteliti.

Berdasarkan uraian latar belakang masalah di atas dapat dirumuskan permasalahan sebagai berikut : (1) apakah air sumur gali di wilayah Kebon Sari Kelurahan Kampung Baru mengandung bakteri Coliform tinja, (2) berapakah nilai MPN ( Most Probable Number ) dari air sumur gali di wilayah Kebon Sari Kelurahan Kampung Baru.

\section{Metode}

Penelitian ini adalah penelitian deskriptif, yang bertujuan untuk mengetahui ada tidaknya bakteri Coliform tinja pada air sumur gali dan menentukan nilai MPNnya (Most Probable Number). Populasi dalam penelitian ini adalah air sumur gali di wilayah Kebon Sari Kelurahan Kampung Baru Singaraja, sedangkan sampel dalam penelitian adalah beberapa air sumur gali yang diambil dengan teknik Area Sampling. Sampel air sumur gali yang diambil sebanyak 9 titik, dimana 5 titik diambil di wilayah Kebon Sari Atas dengan jalan 4 titik diambil disetiap ujung dan 1 titik di tengah, sedangkan 4 titik berikutnya diambil di wilayah Kebon Sari Bawah dengan jalan 3 titik diambil di setiap ujung dan 1 titik di tengah. Untuk dapat menganalisis sampel maka diperlukan persiapan. Persiapan ini meliputi persiapan alat yang berupa pipet ukur $10 \mathrm{ml}$, gelas kimia $250 \mathrm{ml}$,pipet ukur $1 \mathrm{ml}$, tabung durham, pipet ukur $5 \mathrm{ml}$, batang pengaduk terbuat dari gelas, neraca ohaus, botol uji $250 \mathrm{ml}$, tabung reaksi, lampu spritus, otoklaf, oven, inkubator, kapas.sedangkan untuk persiapan bahannya berupa medium lactose broth, medium brilliant-green bile lactose broth, aquades. Air sumur yang dijadikan sampel dimasukkan ke dalam media lactose broth yang dilakukan pada tahap pendugaan dan sampel yang positif diduga mengandung bakteri coliform tinja yang ditandai dengan adanya gelembung pada tabung durham di masukkan ke dalam media brilliant-green bile lactose broth pada tahap penegasan untuk mengetahui positif atau tidak mengandung bakteri coliform tinja dan menentukan nilai MPN ( Most Probable Number ). Dari analisis sampel diperoleh data tentang positif tidaknya bakteri coliform tinja di dalam air sumur gali dan nilai MPNnya, yang selanjutnya data ini dianalisis secara deskriptif.

Tahap Persiapan dalam penelitian ini meliputi: a) Pembuatan Larutan Media Lactose Broth Reagen Lactose Broth ditimbang sebanyak 3.25 gram dan dilarutkan dengan aquades sebanyak $250 \mathrm{~mL}$. Larutan media dimasukkan kedalam tabung reaksi yang telah diisi tabung durham sebanyak 23 tabung. disterilkan media didalam autoklap sampai mencapai suhu $250^{\circ} \mathrm{F}$ lalu didinginkan; b) Pembuatan Larutan Briliant-green Bile Lactose Broth, Reagen Briliant-green Bile Lactose Broth ditimbang sebanyak 10 gram dan dilarutkan dengan aquades sebanyak 250 $\mathrm{mL}$. Larutan media dimasukkan kedalam tabung reaksi yang telah diisi tabung Durham sebanyak jumlah tabung yang mengandung gas dalam tes pendugaan. disterilkan media di dalam autoklap sampai mencapai suhu $250^{\circ} \mathrm{F}$ lalu didinginkan.

Tahap Pengambilan Sampel dalam penelitian ini yaitu: Sampel yang digunakan diambil dari air sumur gali di Kelurahan kampung baru. Air yang akan diperiksa di ambil secara representatif, dengan menggunakan botol sampel yang telah disterilisasi pada suhu $180^{\circ} \mathrm{C}$. Botol sampel diberi pemberat dibagian bawah dan bertali $\pm 20 \mathrm{~m}$ yang diikat pada pertengahan botol. Sebelum botol sampel diturunkan kedalam sumur, mulut botol dipanaskan dengan nyala api untuk menghindari adanya bakteri disekitar leher botol. Botol diturunkan pelan-pelan sampai mulut botol masuk minimum $10 \mathrm{~cm}$ kedalam air. Setelah terisi penuh, botol diangkat dan isi 
dibuang sampai volume sampel air menjadi 2/3 volume botol. Kemudian leher botol dipanaskan kembali dengan nyala api dan dibungkus.

Tahap Analisis Sampel Pada tahap analisa sampel ini yang dilakukan meliputi 2 tahap yakni, tahap pendugaan dan tahap penegasan. a) Tahap Pendugaan, Tahap pendugaan terdiri dari: Inokulasi Sampel, Media yang telah siap, ditambahkan sampel air uji sebanyak $10 \mathrm{~mL}$ (5 tabung), $1 \mathrm{~mL}$ ( 1 tabung ) dan $0,1 \mathrm{~mL}$ (1 tabung). Inokulasi dilakukan selama 24 jam dan 48 jam pada suhu $35 \pm 0.5^{\circ} \mathrm{C}$. diamati gas yang tertangkap di dalam tabung durham setelah 24 dan 48 jam; b) Tahap Penegasan, Tahap penegasan terdiri dari: a) Inokulasi Sampel, Media yang telah siap, ditambahkan sampel yang menghasilkan gas (+) pada tahap pendugaan dengan menggunakan loop/ose yang telah dibakar membara. Inokulasi dilakukan selama 24 jam pada suhu $44,5 \pm 0,2^{\circ} \mathrm{C}$. diamati gas yang tertangkap di dalam tabung durham setelah 24 jam pada suhu $44,5 \pm 0,2^{\circ} \mathrm{C}$; b) Penentuan nilai MPN, Dihitung jumlah tabung positif yang mengandung bakteri Coliform tinja. Kemudian jumlah tabung positif dikomparasikan dengan tabel dari nilai MPN.

Terakhir yaitu Teknik Analisa Data, Data yang didapat dalam penelitian ini dianalisis secara deskriptif, berupa jumlah tabung positif yang ditandai dengan adanya gelembung gas pada tabung, serta nilai MPN air sumur gali yang dikomparasikan dengan tabel dan dicari harga rata-ratanya dengan rumus :

$$
M e=\frac{\sum X}{n}
$$

Keterangan :

$$
\begin{aligned}
& \text { Me }=\text { Rata-rata nilai MPN } \\
& \mathrm{X}=\text { Nilai MPN } \\
& \mathrm{n}=\text { Jumlah Sampel( Sugiyono, 1992,47) }
\end{aligned}
$$

\section{Hasil dan Pembahasan}

Penelitian ini merupakan penelitian deskriptif, yang dilakukan dalam dua tahap. Tahap pertama merupakan tahap pendugaan yang digunakan untuk menduga ada tidaknya bakteri Coliform tinja yang terdapat dalam air sumur. Dari ke-9 sumur yang dijadikan sampel seluruhnya positif diduga mengandung bakteri Coliform tinja, dengan jumlah tabung setiap sampel adalah 7 tabung. Adapun hasil tahap pendugaan secara lengkap disajikan pada Tabel 1.

Tabel 1. Penentuan Jumlah Tabung Positif pada Tahap Pendugaan

\begin{tabular}{llllllllll}
\hline $\begin{array}{l}\text { No Sampel Air } \\
\text { Sumur Gali di Titik }\end{array}$ & 1 & 2 & 3 & 4 & 5 & 6 & 7 & 8 & 9 \\
\hline $\begin{array}{l}\text { Jumlah Tabung } \\
\text { Positif }\end{array}$ & 7 & 7 & 7 & 7 & 7 & 7 & 7 & 7 & 7 \\
\hline
\end{tabular}

Dalam penelitian tahap kedua yang merupakan tahap lanjutan dari tahap penelitian pertama bertujuan untuk menegaskan apakah air sumur gali memang benar mengandung bakteri Coliform tinja. Dari 9 sumur yang dijadikan sampel semuanya positif mengandung bakteri Coliform tinja. Pada tahap ini juga ditentukan nilai MPN (Most Probable Number). Adapun nilai MPN (Most Probable Number) dari ke 9 sumur disasjikan pada tabel 4.2.

Tabel 2. Data Hasil Nilai MPN (Most Probable Number) Bakteri Coliform Tinja

\begin{tabular}{lccccccccc}
\hline No Sampel & 1 & 2 & 3 & 4 & 5 & 6 & 7 & 8 & 9 \\
\hline $\begin{array}{l}\text { Nilai } \\
\text { MPN }\end{array}$ & 240 & 240 & 240 & 240 & 174 & 240 & 108 & 240 & 240 \\
\hline Ket & $\begin{array}{c}\text { Be- } \\
\text { resiko }\end{array}$ & $\begin{array}{c}\text { Be- } \\
\text { resiko }\end{array}$ & $\begin{array}{c}\text { Be- } \\
\text { resiko }\end{array}$ & $\begin{array}{c}\text { Be- } \\
\text { resiko }\end{array}$ & $\begin{array}{c}\text { Be- } \\
\text { resiko }\end{array}$ & $\begin{array}{c}\text { Be- } \\
\text { resiko }\end{array}$ & $\begin{array}{c}\text { Be- } \\
\text { resiko }\end{array}$ & $\begin{array}{c}\text { Be- } \\
\text { resiko }\end{array}$ & $\begin{array}{c}\text { Be- } \\
\text { resiko }\end{array}$ \\
\hline
\end{tabular}


Nilai MPN rata-rata adalah:

$$
M e=\frac{1962}{9} \quad M e=218
$$

Dari hasil analisa data yang dilakukan pada tahap pendugaan dengan menggunakan larutan lactosa broth sebagai media didapatkan seluruh sampel positif diduga mengandung bakteri Coliform tinja. Pada tahap pendugaan ini adanya tabung positif belum menyatakan bahwa air sumur gali di wilayah Kebon Sari Kelurahan Kampung Baru dinyatakan positif mengandung bakteri Coliform tinja. Karena pada tahap ini tidak hanya bakteri Coliform tinja saja yang dapat mefermentasi lactosa broth selama proses inokulasi tersebut melainkan ada beberapa jenis bakteri yang dapat memfermentasi media, berupa bakteri golongan coliform lain di luar dari tinja binatang berdarah panas, yakni dari tumbuh-tumbuhan dan dari tanah yang juga dapat memfermentasi lactose broth pada suhu $35^{\circ} \mathrm{C}$ yang ditunjukkan juga dengan terbentuknya gelembung gas.

Pada tahap penegasan yang menggunakan medium briliant-green bile lactose broth dalam meninokulasi sampel bertujuan untuk mengetahui ada tidaknya bakteri Coliform tinja. Hal ini dikarenakan medium yang digunakan tersebut hanya dapat difermentasi oleh bakteri Coliform tinja pada suhu $44,5^{\circ} \mathrm{C}$, dan juga disebabkan adanya senyawa brilliant-green yang berguna untuk menghambat pertumbuhan bakteri gram positif dan menggiatkan pertumbuhan bakteri golongan colon. Dari hasil analisa data didapatkan seluruh sampel air sumur gali di wilayah Kebon Sari Kelurahan Kampung Baru positif mengandung bakteri Coliform tinja.

Adanya bakteri Coliform tinja pada air sumur gali di wilayah Kebon Sari Kelurahan Kampung Baru mengindikasikan bahwa air sumur gali tersebut tercemari dan tidak layak digunakan sebagai air minum sesuai dengan Keputusan Menteri Kesehatan Nomor 907/MENKES/VII /2002. Sehingga di dalam pemanfaatan air sumur gali sebagai air minum perlu melakukan perebusan terlebih dahulu ataupun dengan jalan menambahkan desinfektan ke dalam air untuk mendesinfeksi bakteri yang ada di dalam air terutama bakteri Coliform tinja.

Pencemaran bakteri Coliform tinja disebabkan sumur gali di wilayah Kebon Sari dibuat berdekatan dengan tempat tinggal penduduk, sehingga secara tidak langsung jarak pencemar ke sumur akan semakin dekat. Pencemar dalam hal ini bakteri Coliform tinja yang dimaksudkan berasal dari tukad Buleleng yang mengalir di dekat perumahan penduduk, serta adanya septictank yang berdekatan dengan sumur gali penduduk dan adanya pembuatan sumur gali yang tidak memenuhi syarat lokasi yaitu jarak sumur ke pencemar kurang dari 10 meter. Sehingga pencemar tersebut dapat mengalami perembesan menuju ke sumur gali dan akan menyebabkan air sumur gali mengandung atau tercemari oleh bakteri Coliform tinja yang berasal dari pencemar tersebut.

Dilihat dari nilai MPN ( Most Probable Number) yang menunjukkan angka perkiraan terdekat bakteri Coliform tinja yang terdapat di dalam air sumur gali, serta menunjukkan bahwa air sumur tersebut beresiko bagi kesehatan( Anonim,60,2002). Dari hasil analisa data didapatkan nilai MPN pada air sumur gali di wilayah Kebon Sari rata-rata sebesar 218. Nilai ini menunjukkan status kontaminasi bakteriologi beresiko untuk air bersih dan beresiko untuk air minum( Keputusan Menteri Kesehatan No. 907 Tahun 2002 ).

\section{Simpulan dan Saran}

Dari hasil penelitian dapat disimpulkan bahwa: 1) Air sumur gali di wilayah Kebon Sari Kelurahan Kampung Baru positif mengandung bakteri Coliform tinja, 2) Nilai MPN air sumur gali di wilayah Kebon Sari Kelurahan Kampung Baru sebesar 218 yang menunjukkan status kontaminasi bakteriologi beresiko apabila dikonsumsi secara langsung.

Hasil penelitian ini diharapkan dapat memberikan saran bagi: a) Bagi Masyarakat, Agar masyarakat di wilayah Kebon Sari, dalam memanfaatkan air sumur gali sebagai air minum, perlu melakukan perebusan air terlebih dahulu untuk membunuh bakteri yang terdapat di dalam air, ataupun dengan menambahkan desinfektan seperti kaporit, Agar di dalam pembuatan sumur gali masyarakat perlu memperhatikan syarat lokasi dan syarat konstruksi; b) Bagi Pemerintah, Agar pemerintah, dalam hal ini dinas kesehatan Kab. Buleleng, untuk dapat memberikan penyuluhan kepada masyarkat tentang bahaya yang ditimbulkan oleh adanya bakteri colifom tinja dan cara pengolahan air unutuk mendapatkan air yang sesuai dengan standar PERMENKES No.907/MENKES/VII/2002, dalam rangka meningkatakan derajat kesehatan masyakat. 


\section{Daftar Pustaka}

Alaert, G. dan Sri Sumestri Santika. 1984. Metode Penelitian Air. Surabaya : Usaha Nasional

Kusnadi,2003. Common TextBook Mikrobiologi. Universitas Pendidikan Indonesia : Bandung

Schlegel, Hans G, 1994. Mikrobiologi Umum. Terjemahan Tedjo Baskoro : Allgemeine Mikrobiologie. Gajah Mada Universty Press : Yogyakarta

Slamet Ryadi, 1984. Pencemaran Air. Karya Anda : Surabaya

Sudiana, Manipan Siregar dan Lanang Wiratrma, I Gusti, 2002. Bahan Ajar Kimia

Analisis Air,Singaraja, Jurdik Kimia IKIP Negeri Singaraja

Suriawiria, U., 1996. Air Dalam Kehidupan Dan Lingkungan Yang Sehat. Alumni : Bandung

Sutrisno, Totok, 2002. Teknologi Penyediaan Air Bersih. Rineka Cipta : Jakarta 